ORIGINAL ARTICLE

\title{
Frequency of Color Blindness in Driving License Candidates Presenting in Allied Hospital, Faisalabad for the Year 2019
}

\author{
IFTIKHAR AHMAD ${ }^{1}$, MUHAMMAD NAWAZ ${ }^{2}$, HUZAIFA AKHLAQ ${ }^{3}$, MUHAMMAD AHSEN $^{4}$, NIDA HAIDER ${ }^{5}$, SARFRAZ \\ ANWAR HUSSAIN ${ }^{6}$ \\ ${ }^{1}$ Assistant Professor Department of Ophthalmology Allied Hospital, Faisalabad \\ ${ }^{2}$ Professor Department of Ophthalmology Allied Hospital, Faisalabad \\ ${ }^{3}$ Senior Registrar Department of Ophthalmology Allied Hospital, Faisalabad \\ ${ }^{4}$ Post Graduate Resident (PGR) Ophthalmology Allied Hospital, Faisalabad \\ ${ }^{5}$ M.Phil Optometry Department of Ophthalmology Allied Hospital, Faisalabad \\ ${ }^{6}$ Doctor of Optometry Department of Ophthalmology Allied Hospital, Faisalabad \\ Correspondence to: Dr. Huzaifa Akhlaq, Email:dr.huzaifa.akhlaq@gmail.com, Cell: + 9203217604171
}

\begin{abstract}
Background: Color vision is an integral part of visual functions. Defective color vision may leadto difficulties in daily activities and even choosing and continuing in a certain profession. Colorvision deficiency or blindness may be congenital or acquired due to retinal or optic nerve disorders

Aim: To investigate the frequency of color blindness or weakness in driving license candidates presenting for medical exam, for the year 2019.

Methodology: The study design was descriptive cross sectional and the sampling technique wasnon probability convenient sampling. The place of study was eye outdoor of Allied Hospital,Faisalabad. The sample size was 13,637 based on inclusion criteria. The subjects ranged in agefrom 18 years onwards to a maximum presentation of 76 years with mean age as $30.728 \pm 10.131$. Both genders were included in the study. Visual acuity was tested on Snellen's Chart andrefraction, if needed, was performed to obtain best corrected acuity.

Results: The results of the study showed that most of the subjects had $6 / 6$ vision as $96.6 \%$ in righteye and $96.5 \%$ in left eye, $6 / 9$ as $2.8 \%$ and $2.9 \%$ and $6 / 12$ as $0.3 \%$ and $0.4 \%$ respectively for rightand left eye. The frequency of normal color vision was $94 \%, 4.9 \%$ for red green deficiency and $1.1 \%$ for color blindness.

Conclusion: A frequency of $4.9 \%$ and $1.1 \%$ for color deficiency and color blindness respectively, in drivers, indicates that color vision must be tested to avoid any possible accidents related todeficient color perception.

Keywords: Driving license, colorblindness
\end{abstract}

\section{INTRODUCTION}

Driving is undoubtedly a high demanding visual task, involving both perceptual and motor skills, and it is wel understood that vision provides most of the information, used in driving. A defectivevision, which may be due to refractive errors or ocular pathology, can lead to driving relatedinjuries. Although all visual functions are important, while assessing a driving license candidatefor licensure, but vision seems to play the most important role.

Each country has their own set of requirements for obtaining driving license. There are varioussteps to obtaining the license including the eligibility criteria, which includes the age limit andmedical examination then each license applicant is required to go through the theory and practicaltest for driving. As per the International Council of Ophthalmology, most of the countries consider20/40 i.e., $6 / 12$ on Snellen Chart to be a legal visual acuity limit required for driving ${ }^{1}$. whereas, WHO considers binocular vision to be normal vision for driving ${ }^{2}$. Visual field impairment is amajor factor in denying a driver license in most states of US and Europe. The Guidelines ofEuropean Commission, do not recommend the testing of color vision and have omitted thiscriterion from eye exam for licensing. However, color testing is still a part of exam in some states of US, Canada, Bulgaria and Pakistan ${ }^{3}$.

Received on 17-01-2021

Accepted on 03-05-2021
According to the national guidelines for driving licensing, Pakistan, the eye test for licensingincludes assessment of visual acuity and color vision ${ }^{4}$. Color vision screening is recommended sothat drivers are more able to identify road signs and signals. ${ }^{5}$ Some studies show that drivers withcolor deficiencies are likely to make color confusions as well as have longer reaction time tocolored traffic signals and signs ${ }^{6,7}$.

Color vision is the ability to distinguish between different shades of color. This ability developsby the age of 4 to 6 months at which time babies can see basic colors easily. Usually, the namesof the colors are learned at an early age, however, it does not mean that any two persons have the same color vision ${ }^{8}$.

Color blindness is the inability to distinguish between different colors. It may also be called ascolor deficiency. It is a sex-linked recessive disorder and is more prevalent in males. Color visionhas significant impact on educational, social and professional activities. Color vision screening, atan early age, is important towards choosing a professional education and career ${ }^{9,10}$. Color deficiency varies from one region to another. In most western countries, $8 \%$ men and $0.4 \%$ women suffer with color impairment whereas the frequency is $4 \%$ in African population ${ }^{11,12}$

Color vision deficiency may be congenital or acquired. Diseases such as diabetic retinopathy,glaucoma, macular degeneration, multiple sclerosis, Alzheimer's etc., or trauma, affecting theoptic nerve, retina or visual cortex may result in acquired color vision defects. Certain drugs 
suchas those used to treat hypertension, infections, nervous and psychological disorders may also affectcolor vision. It is also believed that color ability reduces with age. ${ }^{13}$ Congenital defects affect botheyes equally and are stationary whereas acquired defects are usually progressive.

It is well known that color perception is due to the presence of cones within the human retina andcolor vision defects are classified on the basis of anomaly or absence of one of the three cones thatcode for three primary colors: red, blue and green. Hence, there are generally two types of defects:anomalous trichromacy in which all three types of cones are present but one of the cones isdefective hence making perception of the relevant color, confusing e.g., red green and blue yellowcolor deficiency. The other type of color defect is called as dichromacy wherein only two types ofcones are present and therefore, the perception of color, relevant to missing cone, is absent. Intrichromatic blindness, all three cones are absent and the world is a display of black and white ${ }^{14}$.

There are a number of professions which require the color vision ability to be tested: for safetyor quality assurance purposes e.g., armed forces, civil aviation, navigation, railway workers, drivers, firefighters, medicine, pharmacists, laboratory and engineering technology, fiber andtextile processing, printing, designing, photographic processing etc. ${ }^{9}$ Defective color visionhinders the ability to recognize traffic signal lights and may cause a number of road trafficaccidents. A study conducted in 2016, investigated the effect of color blindness in road trafficaccidents. The results showed that 65 out of 2089 cases, had impaired color vision. It was a five-year long study and concluded that 7 out of 65 drivers had road traffic accidents due to their colorblindness ${ }^{15}$.

An Ethiopian study concluded that color deficient drivers were twice likely to have road accidents as compared to normal and that color vision testing must compulsorily be done in individualsapplying for drivers' license. ${ }^{16}$ The prevalence of color blindness was found to be $2.88 \%$ in anlranian study, out of which most of the cases were deuteranopes ${ }^{17}$. Adekoya and others found Table 1: Status of Visual Acuity of Included Subjects

\begin{tabular}{|l|c|c|}
\hline & \multicolumn{2}{|c|}{ RIGHT VA } \\
\hline & FREQUENCY & PE \\
\hline $6 / 6$ & 13178 & \\
\hline $6 / 9$ & 378 & \\
\hline $6 / 12$ & 36 & \\
\hline $6 / 18$ & 19 & \\
\hline Less than 6/18 & 23 & Percentage \\
\hline \multicolumn{3}{|c|}{13637} \\
\hline \\
Table 2: Frequency of Color Blindness \\
\hline \multicolumn{3}{|c|}{ Frequency } \\
\hline Normal & 12,815 & 94.0 \\
\hline Red green deficient & 669 & 1.9 \\
\hline Color blind & 152 & 100 \\
\hline \multicolumn{2}{|c|}{} \\
\hline
\end{tabular}

\section{DISCUSSION}

The human ability to perceive color depends largely upon a number of processes in the retina andthe brain and any damage or disorders affecting these areas may also result thatout of 399 drivers, $4.3 \%$ were found to have defective color vision ${ }^{18}$.

The aim of present study was to find out the frequency of color blindness in candidates presentingfor driving license at Allied Hospital, Faisalabad during 2019. The test used for assessment ofcolor vision was Ishihara Color test.

\section{METHODOLOGY}

This descriptive cross-sectional study was carried out at eye outdoor of Allied Hospital, Faisalabadfrom January 01, 2019 to December 31, 2019The sampling technique was non probabilityconvenient sampling. Total number of subjects included in the study was 13637. Adults, 18 yearsplus, were included in the study, which happens to be the legal age for acquiring driving license.Every individual that presented for eye test for license was included in the study except for thosewith ongoing ocular or systemic pathology that could affect color vision. Subjects with defectivevisual acuity and/or color vision were examined on slit lamp to rule out any pathology that couldaffect normal color perception, thus, those with acquired color deficiency were excluded from thestudy. The eye test for driving license includes only the testing of Visual Acuity, tested on Snellen'chart placed at 6 meters from the examinee and color vision, tested on Ishihara Color book atreading distance. The data was entered and analyzed on SPSS version 20 and the results wereexplained in terms of mean and frequency.

\section{RESULTS}

13,637 subjects, fulfilling the inclusion criteria, were included in the study. Of these, 13351(97.7\%) were males and $286(2.3 \%)$ were females. Since the legal age limit for acquiring drivinglicense is 18 years, the subjects, hence, ranged in age from 18 years onwards to a maximum of 76years. Thus, the mean age of the subjects was $30.728 \pm 10.131$. in defective colorvision. Most of the color deficiency is congenital. Color vision examination was first introducedin $19^{\text {th }}$ century for on-sea watch keepers and railway workers. This testing was introduced afterfatal accidents that were regarded to be caused due to red green deficiency ${ }^{19}$.

Color vision can be assessed by a variety of tests such as Holmgren Wool Test, Farnsworth Munsell Test, D15 , PV-16 etc. but Ishihara test is the most common method of assessing colorvision because of its easy access and use. This test, hence, can be used for routine color visionscreening and medical examinations. 
The present study was conducted to report the frequency of color blindness in driving licensecandidates. The period of study was 12 months of the year 2019. This study was conducted at eyeoutdoor department of Allied Hospital, Faisalabad. To the best of our knowledge, no other similarstudy has been reported in Faisalabad or Punjab.

\section{CONCLUSION}

A frequency of $4.9 \%$ and $1.1 \%$ for color deficiency and color blindness respectively,in drivers, indicates that color vision must be tested to avoid any possible accidents related todeficient color perception.

Limitation: This local study that has collected data from area of Faisalabad.

Suggestions: Multicentral study should be conducted to calculate exact prevalence of Color blindness in different age groups and these should be defined criteria for driving license candidates regarding their vision and color vision.

Conflict of interest: There is no conflict of interest

Acknowledgment: We acknowledge our outdoor staff and Head of Department for their kind support in retrieving the data.

\section{REFERENCES}

1. Colenbrander A, De Laey J-J. International Council of Ophthalmology. [internet]SaoPaolo, 2006, cited on 14/01/2019. Available at: www.icoph.org , pdf , visionfordriving

2. World Health Organization. Consultation on Development of Standards forCharacterization of Vision Loss and Visual Functioning. [internet]WHO, Geneva,Document WHO/PBL/03.91, (2003). Available at:
www.who.int/ncd/vision2019_actionplan/documents/VisualSt andardsSept03report.pdf.

3. EU report - New standards for the visual functions of drivers. [internet] Brussels, May2005.Available at:http://europa.eu.int/comm/transport/home/drivinglicence/fit nesstodrive/index_en.html

4. Government of Pakistan, Ministry of Communications, National Guidelines for DriverLicensing. [internet] Islamabad, 2019. Cited on 14/01/20. Available at: http://www.roadsafetypakistan.pk/download/nationalguidelines-for-driver-licensing.pdf

5. Heath, G. G., \& Schmmidt, I. (1959). Signal color recognition in color defectiveobservers. American Journal of Optometry Archives American Academy of Optometry,36, 421-437.

6. Atchison, D. A., Pendersen, C., Dain, S., \& Wood, J. M. (2003). Traffic signal colorrecognition is a problem for both protan and deutan color vision deficient's. HumanFactors, 45(3), 495-503.

7. Vingrys, A. J., \& Cole, B. L. (1988). Are color vision standards justified for the transportindustry? Ophthalmic and Physiological Optics, 8, 257-274.

8. American Optometric Association. Infant Vision: Birth to 24 months of age. [internet].Cited on 19/02/20. Available at: https://www.aoa.org/patients-and-public/good-visionthroughout-life/childrens-vision/infant-vision-birth-to-24months-of-age

9. Cumberland P, Rahi JS, Peckham CS. Impact of congenital color vision defects onoccupation. Archives of disease in childhood. 2005;90(9):906-8.

10. Pramanik T, Sherpa MT, Shrestha R. Color vison deficiency among medical students: anunnoticed problem. Nepal Med Coll J. 2010;12(2):81-3.

11. Rajavi Z, Sabbaghi H, Baghini AS, Yaseri M, Sheibani $K$, Norouzi G. Prevalence ofcolor vision deficiency and its correlation with amblyopia and refractive errors amongprimary school children. Journal of ophthalmic \& vision research. 2015;10(2):130. 